\title{
Liver disease complicating severe haemophilia in childhood
}

\author{
K M MCGRATH, J S LILLEYMAN, D R TRIGER, AND J C E UNDERWOOD
}

Department of Haematology, Sheffield Children's Hospital, and Department of Medicine, and Department of Pathology, Sheffield University Medical School

SUMMARY Liver biopsies were performed in 5 boys aged between 2 and 9 years with severe classical haemophilia who had persistently abnormal liver function tests. Abnormal histology was present in all; 4 had chronic persistent hepatitis and the fifth chronic aggressive hepatitis with early cirrhosis. Evidence of previous hepatitis B infection was present in one patient, 3 had antibodies to hepatitis $A$, and 2 had subnormal levels of $\alpha$-1-antitrypsin. Haemobilia occurred as a late complication of biopsy in one. The significance of these findings in young boys is discussed, as is the role of exposure to factor VIII containing blood products. It is concluded that cryoprecipitate should be used in preference to large pool factor VIII concentrates in children with haemophilia.

During the last 2 years it has become apparent that haemophiliacs receiving regular treatment with blood products show a high incidence $(40-60 \%)$ of abnormal liver function tests. ${ }^{1-2}$ Liver biopsies have been performed in some of these patients and they have demonstrated underlying chronic liver damage, ${ }^{2-5}$ ranging from benign chronic persistent hepatitis to chronic aggressive hepatitis and established cirrhosis. The causative agents are thought to be hepatitis viruses (either hepatitis B or non-A, non-B) transmitted in blood products, despite routine screening of donors for hepatitis B antigens. The risk of such contamination is greater in large pool factor VIII (FVIII) concentrates (in which each batch generally exposes the patient to at least 2500 plasma donations) than in an equivalent dose of cryoprecipitate which contains between 5 and 10 donations. The advantages of FVIII concentrates however, particularly in home treatment, are such that these are now the most commonly used form of FVIII replacement.

Most liver biopsies done so far have been in adults who have received numerous treatments with plasma, cryoprecipitate, and FVIII concentrates; however the study of Mannucci et al. ${ }^{4}$ included some children, suggesting that liver damage can occur in the young after a comparatively brief exposure to these agents. For this reason we decided to investigate further the incidence and nature of chronic liver damage in a purely paediatric population of haemophiliacs.

\section{Patients and methods}

All severely affected haemophilia A patients aged between 2 and 16 years had liver function tests, and hepatitis B antigen and antibody screens performed at regular intervals during 1978. Some were treated with FVIII concentrates at home, and the remainder were treated in hospital with both cryoprecipitate and FVIII concentrates.

Any patient who displayed persistently abnormal liver function tests for a period of at least 6 months underwent liver biopsy. None of these patients had symptoms of chronic liver disease or a history of clinical hepatitis, although one (Case 2) had developed greatly increased transaminases in association with abdominal pain and nausea 9 months earlier.

All were screened for inhibitors to FVIII before biopsy. FVIII concentrate sufficient to increase the plasma level to $1.0 \mathrm{U} / \mathrm{ml}$ was given one hour before the procedure and thereafter 12-hourly for 72 hours. In one patient (Case 3) this was increased to 96 hours after complications developed. Each patient was examined for autoantibodies (including antinuclear factor, mitochondrial, and smooth muscle antibodies), immunoglobulin levels, total protein, albumin and globulin levels, and $\alpha$-1-antitrypsin levels.

Liver function tests performed included serum bilirubin, alkaline phosphatase, serum alanine transaminase, and serum aspartate transaminase levels. 
Hepatitis B screens were performed for surface antigen $\left(\mathrm{HB}_{\mathbf{s}} \mathrm{Ag}\right)$, and antibodies to surface antigen $\left(\mathrm{HB}_{\mathrm{s}} \mathrm{Ab}\right)$, and core antigen $\left(\mathrm{HB}_{\mathrm{c}} \mathrm{Ab}\right)$ by radioimmunoassay and immunoelectrophoresis.

Liver biopsies were carried out under general anaesthesia using a Klatskin or paediatric Jamshidi needle via a standard percutaneous route after obtaining written informed consent from both parents.

\section{Results}

Of 18 patients investigated, 5 were found to have persistently abnormal liver function tests, 4 had fluctuating abnormal results, and 9 had normal liver function on each assessment.

The 5 patients with persistently abnormal liver function underwent liver biopsies, the results of which are given in the Table. Four of the 5 patients (Cases

Table Comparison of biochemical data, FVIII concentrate exposure, and liver histology

\begin{tabular}{|c|c|c|c|c|c|c|c|c|c|c|}
\hline \multirow[t]{2}{*}{ Case } & \multicolumn{10}{|c|}{ Range of values during preceding 6 months } \\
\hline & $\begin{array}{l}\text { Age } \\
\text { (years) }\end{array}$ & $\begin{array}{l}\text { Bilirubin } \\
(\mu \mathrm{mol} / l)\end{array}$ & $\begin{array}{l}A S T \\
(U / m l)\end{array}$ & $\begin{array}{l}A L T \\
(U / m l)\end{array}$ & $H B A g$ & $H B A b$ & $H A A b$ & $\begin{array}{l}\text { Concentrate } \\
\text { exposure } \\
\text { (no of batches) }\end{array}$ & $\begin{array}{l}\alpha-1-A n t i t r y p s i n \\
(g / l)\end{array}$ & $\begin{array}{l}\text { Biopsy histological } \\
\text { diagnosis }\end{array}$ \\
\hline 1 & 7 & $7-22$ & $38-160$ & $46-217$ & $\begin{array}{l}\text { S negative } \\
\text { C negative }\end{array}$ & $\begin{array}{l}\text { S negative } \\
\text { C negative }\end{array}$ & Positive & 45 & $1 \cdot 3$ & $\begin{array}{l}\text { Chronic persistent } \\
\text { hepatitis with some } \\
\text { fibrosis }\end{array}$ \\
\hline 2 & 9 & $7-14$ & $15-90$ & $15-378$ & $\begin{array}{l}\text { S negative } \\
\text { C negative }\end{array}$ & $\begin{array}{l}\text { S negative } \\
\text { C negative }\end{array}$ & Positive & 19 & $1 \cdot 9$ & $\begin{array}{l}\text { Chronic persistent } \\
\text { hepatitis }\end{array}$ \\
\hline 3 & 10 & $7-17$ & $61-201$ & $41-354$ & $\begin{array}{l}\text { S negative } \\
C \text { negative }\end{array}$ & $\begin{array}{l}\text { S positive } \\
\text { C positive }\end{array}$ & Negative & 19 & $1 \cdot 4$ & $\begin{array}{l}\text { Chronic active hepatitis } \\
\text { with early cirrhosis }\end{array}$ \\
\hline 4 & 2 & $4-13$ & $47-89$ & $63-115$ & $\begin{array}{l}\text { S negative } \\
C \text { negative }\end{array}$ & $\begin{array}{l}\text { S negative } \\
\text { C negative }\end{array}$ & Positive & 14 & $1 \cdot 9$ & $\begin{array}{l}\text { Chronic persistent } \\
\text { hepatitis }\end{array}$ \\
\hline Toum 1 & 3 & $6-13$ & $66-142$ & $58-159$ & $\begin{array}{l}S \text { negative } \\
C \text { negative }\end{array}$ & S negative & Negative & 13 & $1 \cdot 8$ & $\begin{array}{l}\text { Chronic persistent } \\
\text { hepatitis }\end{array}$ \\
\hline Normal & & $<20$ & $<30$ & $<30$ & Negative & Negative & Negative & 一 & $1 \cdot 8-3 \cdot 0$ & \\
\hline
\end{tabular}

Conversion : SI to traditional units $-\alpha-1$-antitrypsin: $1 \mathrm{~g} / 1 \approx 100 \mathrm{mg} / 100 \mathrm{ml}$. Bilirubin: $1 \mu \mathrm{mol} / 1 \approx 0.058 \mathrm{mg} / 100 \mathrm{ml}$.

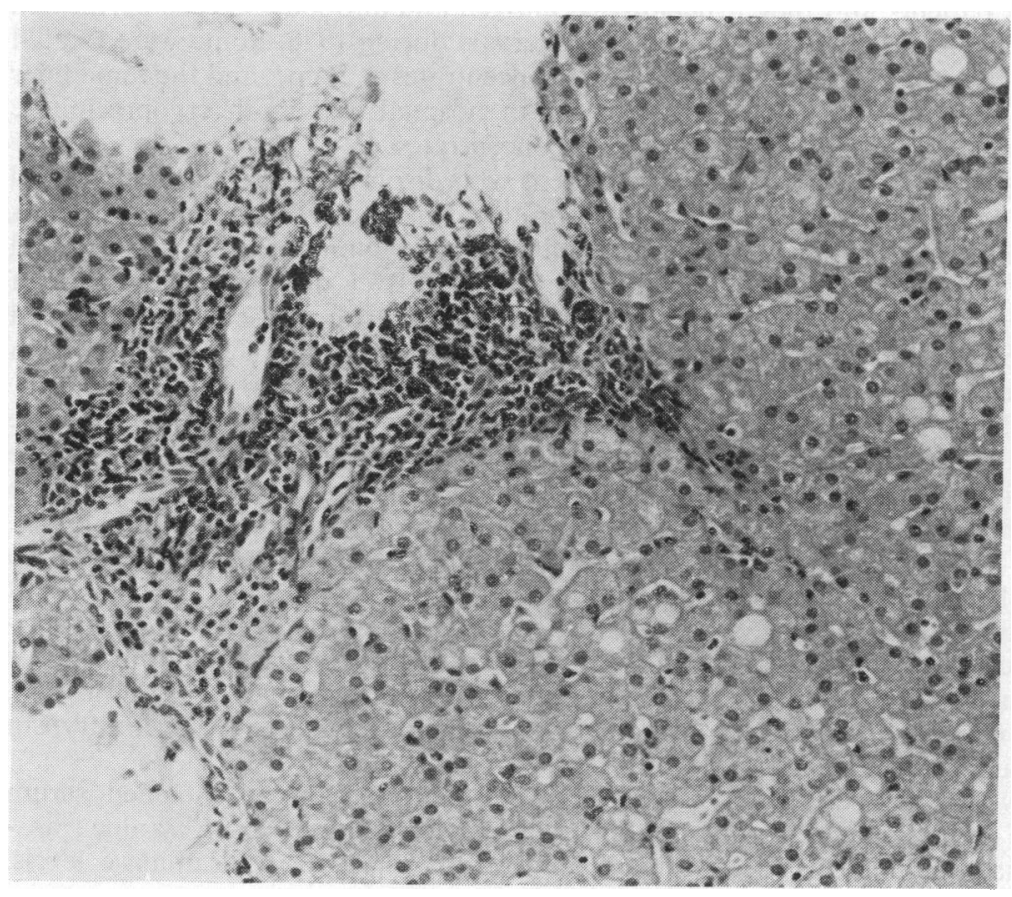

Fig. 1 (Case 1). Dense inflammatory cell infiltration of portal tract, smoothly demarcated from lobular edge. Slight fatty change is present within the lobule. Chronic persistent hepatitis. (Haematoxylin and eosin $\times 400$ ). 


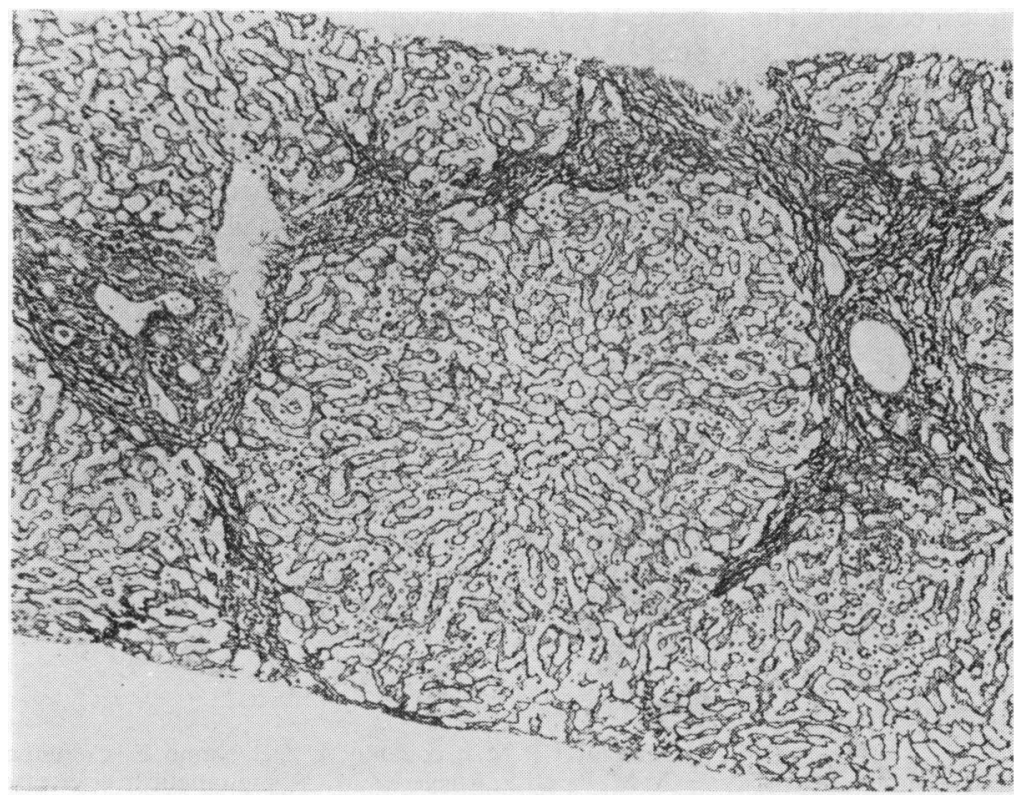

Fig. 2 (Case 3). Disruption of hepatic architecture by bridging fibrosis and incipient nodule formation. Chronic aggressive hepatitis. (Reticulin $\times 160)$.

$1,2,4$, and 5) had histological evidence of chronic persistent hepatitis (Fig. 1), but Case 3 had chronic aggressive hepatitis and evidence of early cirrhosis (Fig. 2), with a few diatase resistant periodic acidSchiff-positive granules.

Only one patient (Case 3 ) had serological evidence of a previous hepatitis $B$ infection, and his serum contained both $\mathrm{HB}_{\mathrm{s}} \mathrm{Ab}$ and $\mathrm{HB}_{\mathrm{c}} \mathrm{Ab}$. Two patients (Cases 1 and 3) had moderately reduced amounts of $\alpha$-1-antitrypsin and were found to be PiMS and MZ respectively. Cases 1,2 , and 4 had hepatitis A antibodies present in their sera, but no evidence of hepatitis B was found. Immunoglobulin levels, total protein, albumin, and globulin levels were normal in all 5 patients. No autoantibodies were detected.

Four biopsies (Cases 1, 2, 4, and 5) were carried out without complication. Case 3 however, returned 6 days later with nausea, blood-stained vomiting, right hypochondrial pain, and tenderness. Examination showed slight jaundice and $5 \mathrm{~cm}$ hepatomegaly with no splenomegaly. The serum bilirubin, alkaline phosphatase, serum alanine and aspartate transaminases were greatly raised compared with previous levels. He was treated with FVIII replacement and remained in bed for 3 days. 24 hours after stopping treatment with FVIII he passed a large melaenic stool and his haemoglobin fell from $11 \cdot 1$ to $8 \cdot 4$ $\mathrm{g} / \mathrm{dl}$. Barium meal and gastroscopy were normal, and there were no oesophageal varices. The gastrointestinal bleeding settled with further FVIII replacement and bed rest, but 4 days later he developed severe right hypochondrial pain and became febrile. A globular mass was palpable in the right hypochondrium extending below the liver edge. Ultrasound examination demonstrated an enlarged gall bladder containing blood clots on the posterior wall. He was treated with intravenous ampicillin and the mass gradually became impalpable. He is currently well, liver function tests have returned to prebiopsy levels, and further ultrasonography shows a normal-sized gall bladder.

\section{Discussion}

The frequency of abnormal liver function tests in our population of paediatric haemophiliacs was $50 \%$ which, despite the relatively short exposure to FVIII replacement therapy, is similar to the incidence of $60 \%$ reported in adults. In half our children with deranged liver biochemistry this had been persistently abnormal for a period of at least 6 months and in each such case liver biopsy confirmed underlying chronic liver damage, ranging from chronic persistent hepatitis to chronic aggressive hepatitis with early cirrhosis. These findings are again in keeping with those of previous studies in adults in which chronic liver disease was found in all patients biopsied.

The major difference in our study was the age range of the affected population (2-9 years), and the significance of abnormal liver histology may be much greater when it occurs in young children with 
an otherwise relatively normal life expectancy. The natural history of chronic persistent hepatitis is uncertain but progression to chronic active hepatitis has been reported, ${ }^{6}$ and the prognosis of this disease in a young population who face continued exposure to the causative agents for many years is unknown.

Only one of our patients had serological evidence of a previous infection with hepatitis $B$ virus, whereas in previous studies ${ }^{3-5} 7$ more than $80 \%$ of patients with chronic liver disease had either $\mathrm{HB}_{\mathrm{s}} \mathrm{Ag}, \mathrm{HB}_{\mathrm{s}} \mathrm{Ab}$, or $\mathrm{HB}_{\mathrm{c}} \mathrm{Ab}$ present in their sera. Again this may reflect the age of our patients who had mainly been exposed to concentrates prepared since the introduction of routine screening of donations for hepatitis $B$ antigen, and it may be that non- $A$ nonB hepatitis will now become more common than hepatitis B infection. Three patients had antibodies to hepatitis A but McVerry et al. ${ }^{8}$ showed that there is no correlation between the incidence of this antibody and abnormal liver function tests in haemophiliacs.

Two patients (Cases 1 and 3) had a deficiency of $\alpha-1$-antitrypsin, being PiMS and MZ respectively. Such a heterozygous phenotype occurs in $3 \%$ of the population, with only 2 reported cases of an association with juvenile cirrhosis, ${ }^{9-10}$ but nevertheless the finding of 2 patients with this type of deficiency in a small sample warrants further investigation of a possible relationship between reduced $\alpha$-1-antitrypsin levels and chronic liver disease in haemophiliacs.

No complication of liver biopsy had been reported in haemophiliacs previously studied, but one of our patients (Case 3), developed clinical features consistent with haemobilia 6 days after biopsy. His initial presentation with features of acute hepatitis probably resulted from an intrahepatic bleed which was contained by FVIII replacement. When this treatment was stopped a further bleed occurred discharging down the biliary tree into the gall bladder and bowel. This is not unknown as a complication of liver biopsy and is often delayed for 2-14 days after the procedure, and may therefore occur after the period of FVIII replacement covering the biopsy.

This study suggests that only brief exposure to FVIII concentrates (13-45 batches) is necessary to produce chronic liver damage in at least $25 \%$ of haemophiliacs requiring regular treatment. As children usually receive treatment in hospital until considered suitable for treatment at home, we recommend such patients should, if possible, be treated with cryoprecipitate in preference to large pool FVIII concentrates until the significance of the chronic liver damage is better understood, or until such FVIII concentrates have been refined to exclude viral hepatitis agents.

We believe that biopsy is justified in patients with haemophilia in cases in which this is indicated on currently accepted hepatological grounds and if full precautions are taken. While none of our patients has so far received treatment as a result of this investigation, corticosteroids were seriously considered in Case 3 and may yet be given. The severity of histological disease cannot be predicted by serum transaminase levels, and biopsy, with all its attendant hazards, is the only way of identifying those patients who might require treatment. Such patients may not be so few and far between, and may comprise an expanding number with a life shortening iatrogenic disease.

\section{References}

1 Mannucci P M, Capitanio A, Del Ninno E, Colombo M M, Pareti F, Ruggeri Z M. Asymptomatic liver disease in haemophiliacs. J Clin Pathol 1975; $28: 620-4$.

2 Levine P H, McVerry B A, Attock B, Dormandy K M. Health of the intensively treated haemophiliac with special reference to abnormal liver chemistries and splenomegaly. Blood 1977; 50: 1-9.

3 Spero J A, Lewis J H, van Thiel D H, Hasiba U, Rabin B S. Asymptomatic structural liver disease in hemophilia. N Engl J Med 1978; 298: 1373-8.

4 Mannucci P M, Ronchi G, Rota L, Colombo M. A clinicopathological study of liver disease in haemophiliacs. J Clin Pathol 1978; 31 : 779-83.

5 Preston F E, Triger D R, Underwood J C E, et al. Percutaneous liver biopsy and chronic liver disease in haemophiliacs. Lancet 1978; ii : 592-4.

6 Chadwick R G, Galizzi J, Heathcote J, Cohen B J, Scheuer P J, Sherlock S. The natural history of chronic persistent hepatitis (abstract). Arch Hellenic Med Soc 1977; 3: Supplement, 3.

7 Lesesne H R, Morgan J E, Blatt P M, Webster W P, Roberts H R. Liver biopsy in hemophilia A. Ann Intern Med 1977; 86: 703-7.

8 McVerry B A, Ross M G R, Knowles W A, Voke J. Viral exposure and abnormal liver function in haemophilia. $J$ Clin Pathol 1979; 32 : 377-81.

- Cruz M, Molina J A, Pedrola D, Muñoz-Lopéz F. Cirrhosis and heterozygous $\alpha_{1}$ antitrypsin deficiency in a 4 year old girl. Helv Paediatr Acta 1975; 30: 501-7.

10 Lieberman J, Silton R M, Agliozzo C M, McMahon J. Hepatocellular carcinoma and intermediate $\alpha_{1}$ antitrypsin deficiency (MZ phenotype). Am J Clin Pathol 1975; 64: 304-10.

Correspondence to Dr J S Lilleyman, Department of Haematology, Sheffield Children's Hospital, Sheffeld S10 2TH.

Received 21 June 1979 